\title{
Fostering Phonological Awareness in a Computerized-Tutored Environment for Arabic Speaking First Graders At-Linguistic Risk
}

\author{
Baha Makhoul1,2,3, Elite Olshtain², Raphiq Ibrahim4 \\ ${ }^{1}$ Oranim Academic College of Education, Tivo'n, Israel \\ ${ }^{2}$ The NCJW Research Institute for Innovation in Education, Hebrew University, Jerusalem, Israel \\ ${ }^{3}$ CET-Center for Educational Technology, Tel-Aviv, Israel \\ ${ }^{4}$ The Edmond J. Safra Brain Research Center and The Learning Disabilities Department, University of Haifa, \\ Haifa, Israel \\ Email: baham@cet.ac.il
}

Received 19 February 2015; accepted 1 April 2015; published 7 April 2015

Copyright (C) 2015 by authors and Scientific Research Publishing Inc.

This work is licensed under the Creative Commons Attribution International License (CC BY). http://creativecommons.org/licenses/by/4.0/

(c) (i) Open Access

\section{Abstract}

The current study investigated the efficacy of a computerized-tutored intervention program in fostering phonological awareness skills amongst 40 At-linguistic Risk Arab first graders. In addition, it examines the role of the pupils' motivation on the learning process. For this purpose, the pupils' achievements were assessed at three points during the program's activation. When compared to control, the intervention group showed significantly higher phonological awareness related skills at the end of the scholastic year. When considering the role of motivation, high-motivation pupils outperformed low-motivation pupils and depicted greater progress in phonological awareness development when compared to their peers. The study findings point to the effectiveness of the program in fostering phonological awareness skills and the importance of motivation in maximizing its gains. The interactive nature of the program that was operated in a computerized assisted environment was allowed to bypass the complexity imposed by Arabic diglossic nature and properties. The study findings are discussed in relation to its practical and scientific impact: diagnosis and treatment, research, teaching and material development.

\section{Keywords}

Phonological Awareness, Arabic, At-Linguistic Risk, Tutorship, Computerized Environment, 


\section{Interactive Model}

\section{Introduction}

The Arabic language impose many challenges on Arabic speaking first graders, beginning their reading acquisition, mainly induced by the discrepancy between spoken Arabic (SA) and its literary form (LA) (Asmer, 2001; Ministry of Education, 1989, 1991; Saiegh-Haddad, 2003, 2004). Contrary to SA, formal exposure to LA occurs in school. The existing gap between SA (dialect) and LA is referred to as diglossia (Rosenhoiz, 1998). Standard written Arabic differs from the spoken language (SAV) in its vocabulary, grammar, syntax, combinations, pronunciation, linguistic expressions, and utterance (Ayari, 1996; Ibrahim, 2009; Saiegh-Haddad, 2005; KhamisDakwar \& Froud, 2007). As such, standard written Arabic (MSA) is considered as a second language for the children (see Maamouri, 1998; Ibrahim \& Aharon-Peretz, 2005). Arabic speakers are obligated to learn new words, different pronunciation, detailed grammar rules and correct writing, occurring simultaneously during the first steps of learning to read.

Arabic is also characterized by its complicated orthography: a) the form of the letters changes according to their position in the word; the letters have different forms of writing as a function of their location: initial (ب), medial (ب), final (ب) and an isolated form (ب). b) Some letters have an identical base shape and the difference between them is in the dots number (1, 2, or 3), and in their position (above the letter, beneath it, or within it) (ب). c) The letters can be written in a linear way and in a connected form (طعام = Food). Subsequently, children find it difficult to distinguish between letters. These facts indicate that orthographic acquisition in Arabic necessitates special pedagogical focus and attention and requires explicit instruction in the special features of the language (Abdelhadi, Ibrahim, \& Eviatar, 2011).

As was found in other at risk populations, the socio-economic background of the Arabic speaking population and the lack of exposure to the written language before commencing first grade may affect negatively their achievements. Children who come from a low socioeconomic background, without any preparation to acquire written Arabic, are generally at high linguistic risk, and it is very likely that they will not succeed in becoming efficient readers (Makhoul, 2006, 2012).

Accumulated data in the research of Arabic language points out that due to the unique characteristics of the Arabic language and its structure, great attention needs to be placed on its phonological and contextual aspects (Olshtain \& Makhoul, 2010; Abu-Rabia, 1999, 2000a, 2000b, 2002, 2003). Accordingly, it is important that Arabic teaching methods be based on the principles of the interactive model (Adams, 1991), enabling the learners to cope with the difficulties mentioned above.

\subsection{Phonological Awareness}

Phonological awareness (distinction and identification of the language sounds) is critical for understanding the Alphabetical principle and phoneme-grapheme correspondence. Children should come to realize that graphic sign represents a phoneme, the minimal meaningful unit of the language (e.g. Kozmenski \& Kozmenski, 1999; Adams, 1991; Smith, Simons, \& Kameenui, 2000; Blachman, Ball, Black, \& Tangel, 2000). Phonological awareness has been found to predict reading acquisition (e.g. Bentin, 1997; Hulme, Hatcher, Brown, Adams, \& Stuart, 2002; Caravolas, Hulme, \& Snowling, 2001).

According to Snow et al. (1998), phonological skills are a) Rhyme, which is a linguistic phenomenon that indicates similarity between words, depending on their tonality, which consists of a phoneme, a stress, intonation, and rhythm. b) Segmentation into Syllables, which refers to division of a word into its basic parts. This is an auditory analysis that includes division of a certain word into its syllables and counting of the common syllables in the word (correct sequence). Segmentation of syllables is vital for improving teaching reading because it constitutes a basis for grasping the basic components of the word. c) Segmentation into Phonemes, which refers to separation of sounds or division of a word into its tones. Words' Sounds manipulation reflects one's ability to distinguish between all the sounds/ tones that participate in the formation of a single word, and assists in identification of omission of a phoneme from the word or its substitution by another one.

At first, children acquire the skill of dividing speech into words and words into syllables, followed with the 
ability to divide syllables into phonemes. In order read fluently, the child has to be aware of the division of the word into phonemes that are represented in writing (graphemes). In Arabic, this issue constitutes a special difficulty because of the characteristics of the language and the redundancy of the diacritic signs that are represented in writing. Researchers agree that good ability of segmentation guarantees that the child will be a better reader, and that there are certain developmental patterns that are required for such segmentation. Besides, studies on children with reading disabilities point out difficulties in segmentation of syllables, phonemes; substitution and omission of phonemes; and identification of rhymes (Bryant \& Bradley, 1983; Weismer, 1990; Schneider, Roth, \& Ennemoser, 2000). Children who suffer from severe reading problem find great difficulty in dividing syllables into phonemes. Thus, it is necessary to foster phonological awareness to improve reading skills among struggling readers.

Different studies show that there difficulties in phonological awareness vary. The findings of Yopp (1988, 1992, 1995) and Stanovich, Cunningham, \& Cramer (1984) indicate that tasks that require phonological awareness differ from each other in their level of difficulty, and therefore, their quality of performance is not identical. This means that among certain age there will be differences in performing tasks that are connected in different dimensions of phonological awareness. According to Yopp (1988), two central factors that affect the level of phonological awareness tasks difficulty. The first deals with the amount of memory load set by the task. The second factor refers to the features of phonological units (refers to the position of the phoneme in the word (initial, medial or final), the level of abstraction (a complete word versus a syllable); length of the total unit and the phonological skills (isolation, omission, etc.).

Many pupils start learning at the first grade with very little or no amount of linguistic awareness. These pupils are defined as "At-linguistic risk".

To sum up, the study emphasizes the importance of mastering phonological knowledge as basis for reading acquisition (Blachman, 2000), distinguishing between skillful and poor readers.

The current study focused on developing pedagogical methods to improve phonological awareness of at-linguistic risk Arab children who are at high linguistic risk, in order to minimize reading acquisition failure.

\subsection{Linguistic Risk}

In addition to socio-economic status and demographic conditions, developmental linguistic risk can be related to intrinsic causation (Assink, 1994). Children from low socio-economic status are more likely to commence their formal schooling with poorer literacy skills when compared to their peers from more advantageous socio-economic backgrounds. It has been shown that there is a wide gap in the ability of acquiring academic reading skills between groups from high and low socio-economic background (Aram \& Levin, 2001; Aikens \& Barbarin, 2008; Lombard, 1995). It has been found that socio-economic differences contributed to this gap, because parents from low level income paid less attention to their children's listening to language sounds, initiated less shared reading opportunities, and relied on incidental linguistic development (Rush, 1999; Aram \& Levin, 2001).

The First Grade is the starting point of formal exposure to written language. Learning at this stage is not linear and gradual, but rather a complex developmental process that takes place at varying rates among different children (Korat, 1988; Korat \& Becher, 1997) and can be extremely influenced by the abovementioned factors.

\subsection{Motivation}

One of the problematic characteristics of struggling pupils is their low motivation for learning, a lack of initial motivation or losing it throughout the process; they lose self-esteem and pleasure from independent reading (Snow et al., 1998). Several studies pointed to the contribution of computerized programs for words recognition on raising the motivation level (Roth \& Beck, 1997; Cobb, 2001; Cole \& Hilliard, 2006). Those researchers concluded that motivation is necessary for developing reading achievements. Other researchers indicated that pupils, who have experienced repeated failures in reading, should work in a new environment in order to raise their motivation (McCormick, 1994; Mayer \& Rose, 1998; Wright, 1998; Roth \& Beck, 1987). To sum up, computer-assisted environment has proved its contribution in fostering learning motivation (Chang, 2002; Cotton, 2001; Garcia \& Arias, 2000).

\subsection{The Current Study}

Arab children face difficulties during first stages of reading acquisition because of the Diglossic phenomenon 
and Arabic language complexities. In the case of the Arab learners at primary schools in Israel, the low socioeconomic background of the Arab sector makes the situation even more difficult. In search of a pedagogical approach that can cope with all these difficulties, we decided to develop a computer-assisted in individual tutoring intervention program. $t$ in order to a close follow-up to the development of the individual single learner and due to the proven contribution of tutoring intervention programs to reading processes (e.g., Elbaum \& Vaughan, 2000). In view of this, it was decided to train Pre-service Teachers to be tutors for this specific purpose. Besides, a computerized environment was chosen for two reasons: first, working via computer will be conceived by the pupils as a prize rather than an extra assistance course; second, the forms of the letters on the computer screen will be more obvious and prominent.

The main objective of this study is to examine to what extent an intervention program that is based on a computerized-tutored environment can promote the high-linguistic-risk-learners in a significant way, and improve their ability of reading acquisition as it is reflected in phonological awareness.

\section{Method}

\subsection{Participants}

The participants were Arab first graders from a school in northern Israel. The socio-economic condition of the school population is low, both economically and educationally. The pupils arrive at school with limited knowledge about the world, with low verbal abilities and poor vocabulary, also affected by inadequate t exposure to written standard Arabic. The pupils depicted low phonological awareness skills and they had little awareness of the reading process and the forms of Arabic letters.

By the beginning of the intervention program activation, tests were administered to 60 first graders. Based on their test scores the weakest 40 pupils were selected. Out of the 40 pupils, 20 pupils were randomly selected to participate in the intervention group and were defined as the "Intervention-Group". The other 20 pupils constituted the "Control-Group".

Two months after the pupils started learning, it was possible to receive from the class teachers personal assessments regarding the participating pupils. According to the teachers' reports, the 'target population' pupils were divided into two subgroups:

1) Ten pupils of high level of motivation and cooperation

2) Ten pupils with low level of motivation and cooperation.

In addition to this, according to the tests that were given prior to the commencement of the intervention program, the pupils were divided into three levels of ability: an "Experienced pupil” (highest level); "Advanced pupil" (who can make progress), and "At-Risk pupil" (who has difficulties). The tests that were given before, during and after the intervention program dealt with phonological skill of these three subgroups.

\subsection{The Intervention Program}

\subsubsection{Main Features}

The integration of a computerized environment in the teaching/learning sequence has several important advantages: a) It allows the introduction of the teaching elements on two channels simultaneously - the auditory and the visual (Bowman, 1998). This is a key element in phoneme/grapheme correspondence. b) The use of a word processor creates a friendly environment within which both the tutor and the pupil can manipulate shapes and positions of letter via: addition, erasure and substitution activities. c) While manipulating characters within words it is also possible to focus on morphological features and enhance morphological awareness (Inbar \& Ravid, 1995).

The tutorial perspective in the intervention program has advantages in creating an encouraging environment, and thus provides opportunities for increasing the learner's self-esteem and personal success, leading to increased motivation.

The computerized units of work could consist of a variety of letter oriented, word focused and finally story reading activities. This allowed the program to combine context and reading for comprehension with activities that focused on individual words and letters.

\subsubsection{The Program's Components}

The current intervention program was developed to assist pupils at-risk for reading difficulties (the weaker stu- 
dents in our case). The program consists of 26 meetings (for 13 stories) and was operated in a computer-assisted individual tutoring framework. It is a balanced remedial program that is based on the principles of the interactive model (Adams, 1991). This model suggests that reading and writing acquisition is a process demanding a parallel activation of four processors: the phonological processor (the ability to distinguish and recognize the sounds of the language before referring to the words meanings), the orthographic processor (enables phonemegrapheme matching and reflects the reader's ability to use orthographical sequences in order to access the lexicon without phonological mediation), the semantic processor (processor of word-meaning) and the contextual processor (help the reader to read accurately by relying on the whole idea expressed in the text). The contents of the program were suited to the needs of first grade pupils, aiming to reinforce the four processors that are involved in the process of reading acquisition, in addition to decoding skills

Individual learning is performed under the guidance and training of a tutor who underwent special training. The tutor functions as a guide/ trainer and observes the process of learning. The tutorship environment provided for the individual a guided built-in learning environment.

The process is fixed throughout the program. The tasks in each weekly unit are divided into four basic purposes, each introduced in two weekly sessions: development of contextual ability and meaning, development of orthographic ability, development of phonological skills and tasks whose goal is exercising and deciphering skills that are suited to the reading text and the teaching program of the first grade. There is a diffusive process and a reciprocal contribution between the four parts.

In each meeting, the tutor documents the pupil's answers and the various tools the pupil used. Besides, the methodological notes that were added to each unit assisted him. This environment supports the pupil's teaching process and helps the tutor to cope with the arising difficulties, and enables him to assess his functioning, and the functioning of the pupil, also supplying them with different learning strategies to bypass their source of difficulty.

\subsubsection{A Built-in Sequence Activities}

One of the important characteristics of the program is its built-in sequence of activities. Every meeting starts with a warm-up conversation intended to facilitate communication and relaxed interpersonal connection. The opening is followed by pre-reading activities that is intended to prepare the pupil to acquire comprehension strategies, and arouse in him interest in the story, which he will read with the tutor. At this stage of preparation, there is emphasis on the main-key words by putting emphasis on their semantic and contextual meaning. After these preparatory activities, the tutor and the pupil read the story together on the screen. The tutor moves the cursor on all the words and sentences of the story. Here, there is both an auditory and visual exposure. In the second reading, there is greater emphasis on words and their structure.

After the story has been read twice, the post-reading activities include rehearsal of the story focus and explicit information retrieval, making straightforward inference and Interpretation and interpretation of ideas. Reading the story and the activities around it constitute a part of the meeting that is based on processes of understanding. In the remaining part of the meeting, the emphasis is on the deciphering skill, which consists of three central components: phonological awareness that depends on rhyme, segmentation that is based on syllables and phonemes, and production of sounds. A lot of emphasis is put on identification of the syllables sounds at the beginning of the word and at its end, and later, on similar productions.

Each tutor received a portfolio to document and assessed the progress of the pupil's learning process. The pupil received a CD that included the units of the program. Two weekly sessions were administrated, each for 45 minutes. The activities' instructions are detailed for all tutors where they also receive weekly briefing regarding the content of the sessions and how to cope with problems that come up during the meetings.

\subsection{The Study Questions}

The questions of the study focused on the comparison between the intervention group and the control group, (who were of equal level of knowledge before the activation of the intervention program) in phonological awareness (especially in three skills: syllables segmentation, rhyme awareness and segmentation into phonemes). The Separation between variables enables us to test the reciprocal relations between different skills:

1) To which extent the intervention program that was applied among the intervention group affected the phonological awareness among the pupils in the same group in comparison with the pupils in the control group, 
who worked according to a regular teaching program?

2) To which extent there is a difference between pupils with high motivation and pupils with low motivation in phonological awareness skill?

\subsection{Tools}

Phonological awareness tests were passed in the beginning of the program activation for all the school first graders (five years children and above) in order to choose the study sample. Before and after the activation, the entire sample passed, Arabic translated version of Lapidot, Wahel and Tobol (1996) phonological test was administrated. The test was composed of 11 sections. In each section, three examples were given, in order to ensure that the children understood the task's instructions. The following sub-sets were included rhyme recognition and production; Rhyme production; final syllable recognition (initial phoneme recognition final phoneme recognition; initial phoneme judging; final phoneme judging (initial sound isolation final sound isolation; initial phoneme omission and final phoneme omission. On each subset, one point was granted for each correct answer. An overall average score was calculated.

To compare between the participants, both reliability (test-retest comparisons) and equivalence (correlations between two equal parts of the test) indexes were calculated. Index, which was calculated by test-retest measurements, showed positive correlations between the measurements (.79). Also, the equivalence index-which was calculated by dividing the test into two equal parts and those parts was compared by Pearson correlations: at kindergarten the correlation was positive (.87) between the test parts, and at first grade the correlation was also positive and very high (.94). Alpha-Cronbaoch showed on a high reliability at kindergarten (.92), and between the 11 sections was .76. At first grade, the reliability was 0.98 and between the 11 sections was .79 . Therefore, it was possible to compare a pupil's achievement with his peers.

The validity was tested by content validity: four experts estimated it by filling in a questionnaire. In addition, teacher's evaluations of the pupils' reading level were gathered.

In addition, in order to assess the pupils' progress throughout the program duration, three main skills were assessed at three time-points: segmentation into syllables, segmentation into phonemes and rhyme production:

1) The first measurement was carried at the beginning of the program activation (sessions 1 - 6).

2) The second measurement included children's scores on sessions 11 - 16.

3) The third measurement included the obtained scores on sessions 21 - 26 (meetings 21 - 26).

In every measurement, the tests differed from unit to the other; the items changed in each unit as a function of the unit theme, but the building principals of these items are similar. Every measurement includes the average of every skill of the meetings included in the specific measurement.

\subsection{Procedure}

A phonological awareness test was administrated to all participants prior to the program commencement and after its termination.

The children's progress was monitored at three time points.

\subsection{Statistical Analysis}

To answer the study question, the following analysis was conducted:

1) Comparisons between intervention and control group in phonological awareness test at the beginning and end of the year by t-Test for dependent samples.

2) Description of the overall means of the intervention group in phonological awareness at every measurement, in relation to the child's motivation and performance gradation.

3) Description of the overall means of the intervention group in segmentation into syllables, at every measurement, in relation to the child's motivation and performance gradation.

4) Description of the overall means of the intervention group in segmentation into phonemes, at every measurement in relation to the child's motivation and performance gradation.

5) Description of the overall means of the intervention group in rhyme production, at every measurement in relation to the child's motivation and performance gradation. 


\section{Results}

\subsection{Phonological Awareness: Comparison between the Intervention and Control Groups}

Table 1 shows the findings of the intervention program improved the phonological awareness among the intervention group.

Table 1 points to initially poor phonological skills in both groups where shows no significant difference was found between the intervention group and control group $(t(38)=-.68$, pns). In the post-test, both the intervention group and the control group showed a trend of progress, $(t(19)=-26.07, p<.001),(t(19)=-14.16, p<.001)$, respectively. However, greater gains in phonological skills were observed in the intervention group when compared to the control group $(t(38)=13.51 ; p<.001)$.

Table 2 describes the pupils' achievements according to their level of motivation, both by the beginning and by the end of the year.

From the table above, we can conclude that both subgroups started from a similar point, but pupils with high level of motivation outperformed pupils with low level of motivation in their phonological awareness.

\subsection{Motivation Effect and Development in Phonological Awareness across the Measurements}

Figure 1 describes the differences in functioning in overall phonological skills in the three measurements, according to the level of the pupils' motivation.

As presented in Figure 1, within the intervention group, progress in phonological awareness is noted across the three measurements, independently from the pupils' motivation level (see total bars above).

In the first $m$ measurement, the percentage of assessments in the gradation "At-Risk Pupil" among the highmotivation-pupils is as high as (46.8\%) (Only about 16\% in the gradation of "Experienced Pupil”). Similarly, the percentage of assessments in the same gradation among low-motivation-pupils is $60 \%$, and the percentage of their assessment in the gradation of "Experienced Pupils" is 9.8\%.

In the second measurement, we see that there is a progress among all the pupils. Among the high-motivation-pupils, there is a rise in the percentage of the gradation "Experienced Pupil" to $61 \%$ (only $9 \%$ of their assessments remained at the gradation of "At-Risk Pupil”). In addition, among the low-motivation-pupils, about $44 \%$ of their assessments rose to the gradation of "Experienced Pupil” and only 23.3\% of their assessments remained in the gradation of "At-Risk Pupil”. In other words, in the Second Measurement between the two groups, significant progress was noted in phonological awareness.

The improvement in the pupils' functioning continued to the third measurement amongst all the pupils in the intervention group. In the high-motivation subgroup, an increase was noted in the percentage of pupils in the

Table 1. Main scores on phonological tasks before and after the program activation in both the intervention and control groups.

\begin{tabular}{|c|c|c|c|c|}
\hline & Before Activation & After Activation & \multirow{2}{*}{$d f$} & \multirow{2}{*}{$t$} \\
\hline & M (SD) & M (SD) & & \\
\hline Intervention group $(n=20)$ & $25.90(5.83)$ & $77.05(5.84)$ & 19 & $-26.07^{* * *}$ \\
\hline Control group $(n=20)$ & $27.25(6.73)$ & $47.80(7.72)$ & 19 & $-14.16 * *$ \\
\hline Total $(n=40)$ & $26.58(6.25)$ & $62.43(16.28)$ & 39 & $-13.13^{* * *}$ \\
\hline
\end{tabular}

${ }^{* * * *} p<.001$.

Table 2. Phonological awareness average scores according to the pupils’ level of motivation.

\begin{tabular}{|c|c|c|}
\hline & Before Activation & After Activation \\
\hline & $M(S D)$ & $M(S D)$ \\
\hline Pupils with high level of motivation $(n=10)$ & $26.20(5.59)$ & $79.30(2.95)$ \\
\hline Pupils with high level of motivation $(n=10)$ & $25.60(6.35)$ & 74.80 (7.22) \\
\hline
\end{tabular}




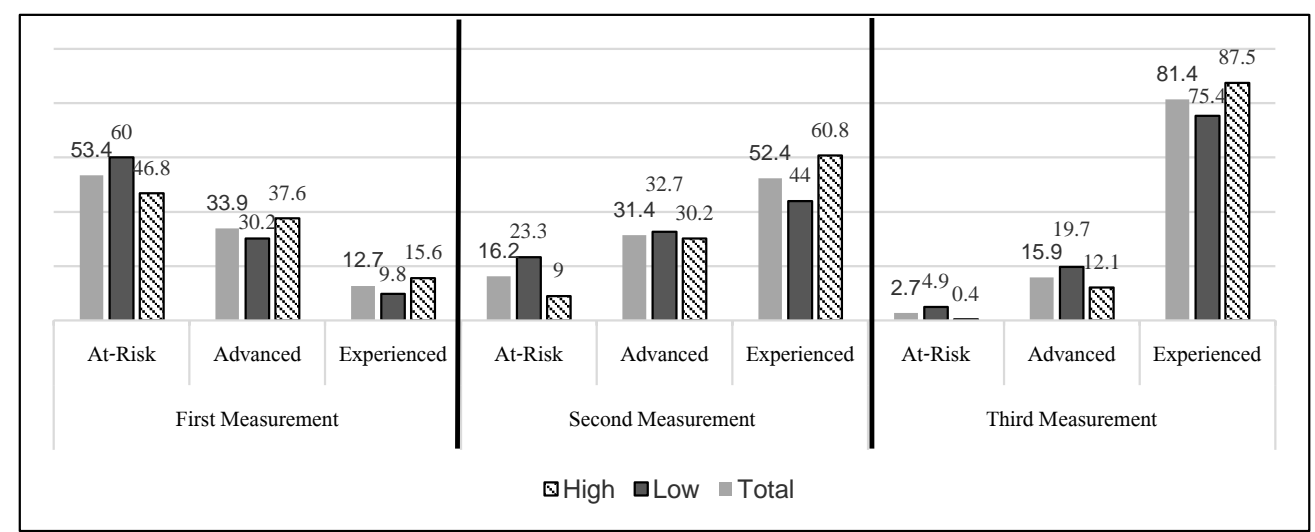

Figure 1. Phonological awareness average scores in each measurement in relation to the pupils’ motivation ${ }^{1}$.

gradation of "Experienced Pupil" (87.5\%). Similar increase was also obtained in the low-motivation subgroup, where $75.4 \%$ of the pupils were ranked as "Experienced Pupil".

To sum up, Figure 1 show on a significant improvement in the sequence of development in the ability of phonological awareness skills, and development of the two subgroups that is obvious through the three measurements. In addition, a difference in the quality of development in phonological awareness skills between the two subgroups of pupils depends on the pupil's motivation. However, in the last measurement, the gap is narrowed to $13 \%$ in the gradation of "Experienced Pupil".

\subsubsection{Description of the Learning-Behavior of the Two Subgroups Regarding the Skill of Segmentation into Syllables}

Here is a description of the differences in Segmentation into syllables in all the measurements, according to the level of the pupils' motivation.

Figure 2 presents segmentation into syllables in each measurement according to the pupils' motivation level. In first measurement, there is difference of about $10 \%$ between the pupils' subgroups (high-motivation/Low motivation) in the gradation of "At Risk Pupil" and "Experienced Pupil”. The percentage of assessment in the gradation of "At Risk Pupil' among the high-motivation-pupils group is about 30\% and the percentage of assessment in the gradation "Experienced Pupil" is $27.1 \%$. However, among the low-motivation-pupils, the percentage of assessment in the gradation "Experienced Pupil" is only about 17\%, and in the gradation of "At Risk Pupil" is $45.3 \%$.

In the second measurement, there is a pattern of rise in the functioning of the two subgroups, from $22.1 \%$ in the first measurement to $68.8 \%$ in the second. However, the pace of progress among the high-motivation-pupils is faster than the pace of progress among their mates in the low-motivation subgroup; the percentage of assessment in the gradation "Experienced Pupil" among the high-motivation-pupils rises to $75.2 \%$ (13\% higher than assessments in the gradation of "Experienced Pupil" among low-motivation-pupils-62.4\%).

In the third measurement, the group of the high-motivation-pupils keep showing quicker progress; the percentage of assessment in the gradation of "Experienced Pupil" in the skill of segmentation into syllable is very high among the high-motivation-pupils (96.2\%). However, among the low-motivation pupils, the percentage of assessment in the same gradation is $83.8 \%$. In spite of the study results show that the skill of segmentation into syllables is the easiest of the other skills of phonological awareness, there is still difference in the functioning between the two groups of pupils as a function of their own motivation.

\subsubsection{Description of the Learning-Behavior of the Two Subgroups Regarding the Skill of Segmentation into Phonemes}

Here is a description of the differences in functioning in phonological skill: segmentation into phonemes in all the measurements, according to the pupils' level of motivation.

From Figure 3, we conclude that the percentages of assessments in all the categories of gradation in phonological awareness indicate that the segmentation into phonemes in every measurement changes and is affected by

${ }^{1}$ Percentages are based on 630 answers in each measurement: 7 items multiplied by 3 skills, multiplied by 3 stories, multiplied by 10 pupils. 


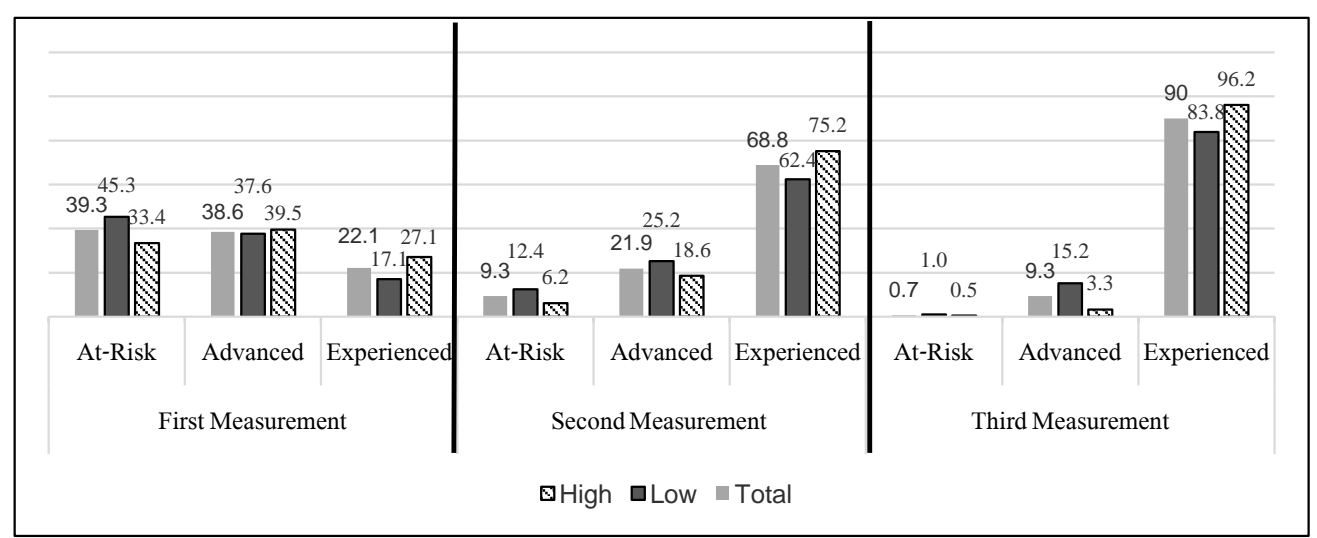

Figure 2. Phonological awareness-segmentation into syllables: percentages in each measurement according to the pupils' motivation ${ }^{2}$.

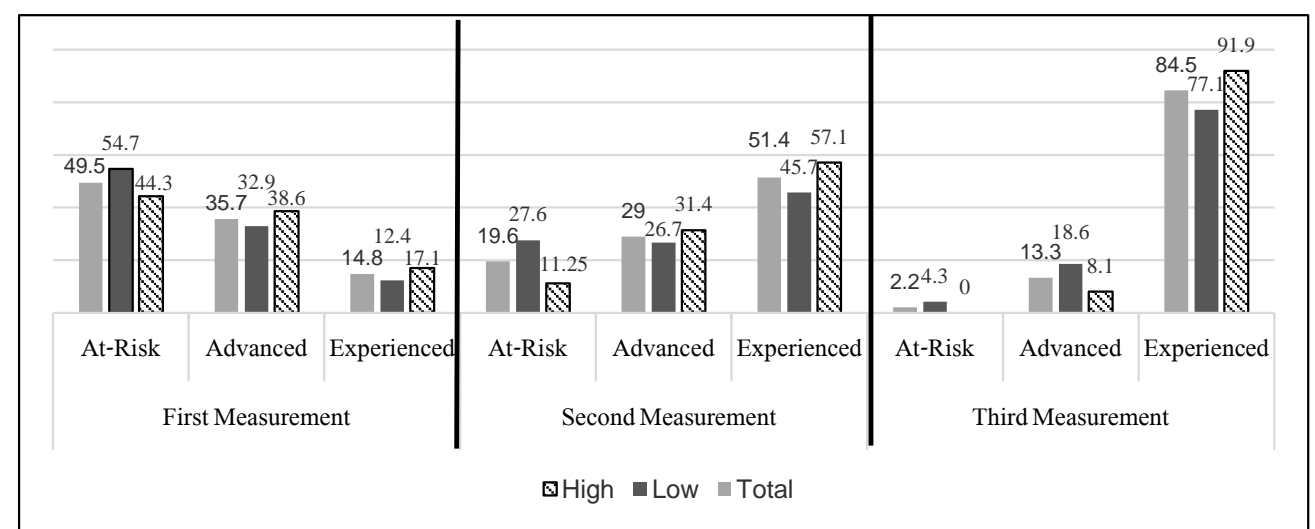

Figure 3. Phonological awareness-segmentation into phonemes: percentages in each measurement according to the pupils' motivation ${ }^{3}$.

the pupils' motivation. In this skill, the results point to a great difference in the progress rate of the two subgroups, especially in the last (third) measurement.

In the first measurement, $44 \%$ of the assessments of the high-motivation-pupils, and more than half (55\%) of the assessments of the low-motivation-pupils were in the gradation of "At-Risk Pupil" (i.e. they did not know the answer or gave a wrong answer).

In the second measurement, the progress is clear between the two subgroups of pupils; about $57.1 \%$ of the assessments of the high-motivation-pupils made progress to the gradation of 'Experienced Pupil', while progress of the assessments of the low-motivation-pupils was only 45.7\%. Accordingly, the percentage of assessment in the gradation of "At Risk Pupil" among the high-motivation-pupils is twice higher (27.6\%) than the percentage among the low-motivation-pupils (11.25\%). It is noticeable that among the high-motivation-pupils there is higher ability to cope with the difficulty when compared to the low-motivation-pupils.

In the third measurement, progress is seen in both subgroups. Among the high-motivation pupils, $91.9 \%$ of the assessments were functioning as "Experienced Pupil”, and only 8.1\% of them were "Advanced Pupils" (who gave correct answers after receiving mediation or assistance). In the low-motivation subgroup, only $77.1 \%$ of the assessments were functioning as "Experienced Pupils" and 18.6\% remained as "Advanced Pupils". With assistance and support, these pupils succeeded in finding out the correct answer.

It is also clear that in the skill of segmentation into phonemes there is a difference in the functioning between the two subgroups in favor of the high-motivation-pupils. In addition, it is possible to conclude that the pupils found difficulty in this skill more than in the segmentation into syllables skill.

\footnotetext{
${ }^{2}$ Percentages are based on 630 answers in each measurement: 7 items multiplied by 3 skills, multiplied by 3 stories, multiplied by 10 pupils. ${ }^{3}$ Percentages are based on 210 answers in each measurement: 7 items multiplied by 3 stories, multiplied by 10 pupils.
} 
The high-motivation subgroup made a progress in syllable segmentation across the three measurements, which was higher than their progress in phoneme segmentation. Same pattern of results was noted among the low-motivation-pupils. They showed greater improvement in syllable segmentation when compared to phoneme segmentation. Ultimately, higher rate of progress was obtained by the high-motivation subgroup in comparison to the low-motivation subgroup.

\subsubsection{Description of the Learning-Behavior of the Two Subgroups Regarding the Skill of Rhyme Production}

Here is a description of the differences in functioning in Phonological Skills: Production of Rhymes in all the measurements, according to the pupils' motivation.

From Figure 4, we conclude that rhyme production was the most difficult skill. From the first measurement it is possible to see a significant difference in the nature of the pupils' performance in the two subgroups. In the lowmotivation subgroup, $80 \%$ of the assessments were in the gradation of "At Risk Pupil”, and only $20 \%$ remain in the gradation of "Advanced Pupil" (which refers to success after mediation and support). In comparison, $62.8 \%$ of the assessments in the high-motivation subgroup were in the gradation of "At Risk Pupil” and 34.8\% were in the gradation of "Advanced Pupil”. Hence, difference between the two subgroups is notable in this skill. In the second measurement, there is a progress in performance. However, significant difference between the subgroups is still observed. In the third measurement, the gap between the pupils' groups (high and low motivation) is clear, pupils with high level of motivation are more in "Experienced pupil" gradation in comparison to pupils of low level of motivation.

\section{Discussion}

In order to examine the phonological skills of the intervention group and control group before and after participation in the program, phonological awareness test (consisted 11 sections) was administrated. Furthermore, in order to assess the progress within the intervention group, three different skills were assessed (segmentation into syllables, segmentation into phonemes and rhyme production) at three time points (See Method section in addition, observational data was collected by the tutors).

\subsection{The Effect of the Intervention Program on Phonological Awareness Development}

The study findings indicated that a built in intervention program succeeded in improving the pupils' phonological skills, that are considered necessary for reading acquisition; a significant improvement was noted in the intervention group in comparison to their initial performance (before the program activation) and beyond the natural development occurred in the control group. Our findings are consistent with previous data, pointing to the beneficial outcomes of fostering both phonological skills and written script recognition (Ehri, Wunes, Willows,

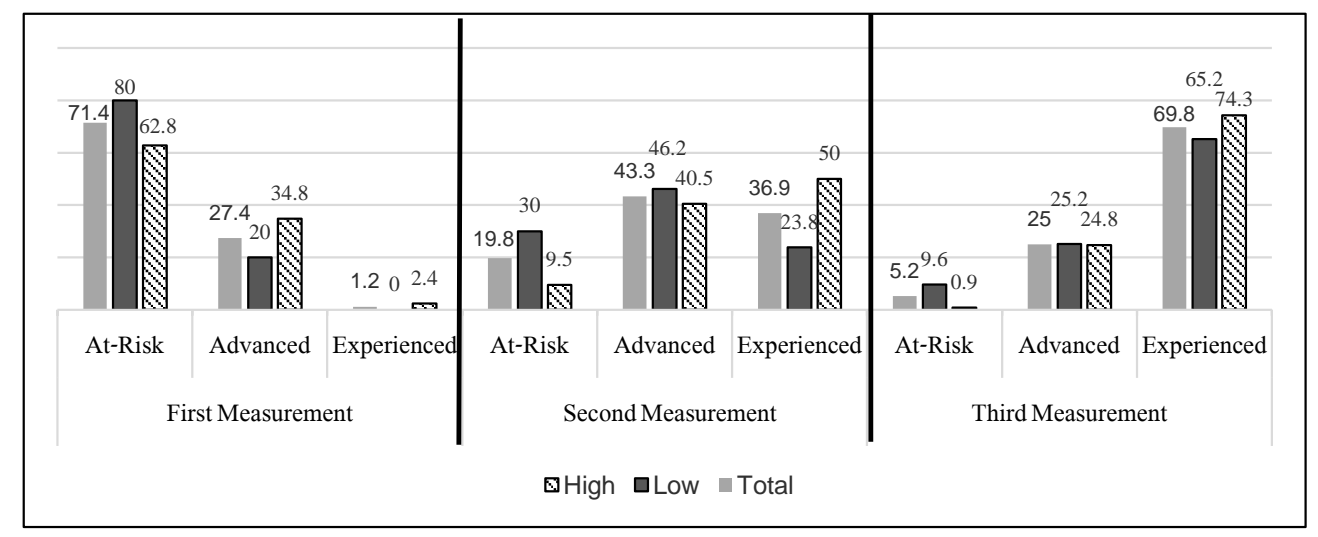

Figure 4. Phonological awareness-rhyme production: Percentages in each measurement according to the pupils' motivation ${ }^{4}$.

${ }^{4}$ Percentages are based on 210 answers in each measurement: 7 items multiplied by 3 stories, multiplied by 10 pupils. 
Schuster, Zadeh, \& Shanahan, 2001; Hurford et al., 1994; Snow, Burns, \& Griffin, 1998). As suggested by, Olshtain and Zuzuvski (2003). The results indicate that schools should create a reading supported environment for pupils from low socio-economic.

In several studies, Abu-Rabia (1999, 2000a, 200b, 2002, 2003) indicated that in order to cope with the difficulties imposed by Arabic language complexity, one should take into account different compensating factors : a) fostering phonological aspects and improving contextual comprehension and b) Developing teaching methods in the basis of the interactive model.

In this study, the interactive model of Adams (1991) was chosen to represent the interactive approach, which perceives reading, process as a process that relies on synchrony between four processors: phonology, orthography, meaning and context. Thus, activities addressing these precursors were simultaneously incorporated in the different units. The progress obtained in the pupils' performance provides an evidence for the adequacy of the interactive approach to promote reading acquisition in Arabic.

\subsection{The Contribution of Pupils' Motivation on the Improvements in Phonological Awareness}

In general, Motivation is a core component in learning, especially in reading instruction. g. It has been suggested, that a reduction in motivation level occurs to all children at the end of elementary school. Most of the reading problems amongst teenagers and adults result from difficulties that can be avoided, so we should focus on motivation fostering in early stages (Snow, Burns, \& Griffin, 1998). Perceived Self-efficacy for reading was encountered to correlate with literacy achievements (Olshtain \& Zuzuvski, 2003). The motivation importance stems from the idea that it determines the amount of invested efforts when the child faces difficulties.

The current findings show an improvement in all three measurements within the study that is seen to be also affected by the pupils' motivation level. In the last measurement, higher gains were noted among the highly motivated subgroup when compared to the low-motivation level subgroup.

Concerning the three assessed phonological skills, by the end of the activation, $96 \%$ of the highly motivated pupils, reached the "Advanced pupil" gradation in syllable segmentation skill. In contrast, only $84 \%$ of the pupils in the low motivation subgroups reached the "Advanced pupil" gradation. Although Syllable segmentation is considered as being the easiest manipulation to be conducted on word's sounds, yet performance on this task seemed to be impacted by motivation level where differences in performance was encountered between the low and high motivation subgroups.

A similar pattern was found in the phoneme segmentation measure, which is considered harder than syllable segmentation manipulation (Liberman, Shankweiler, Fisher, \& Carter, 1974). It was noted that the progress rate of low-motivation pupil is slower than high-motivation pupils. The most prominent gap between the subgroups is seen especially in the third measurement. This finding raises the importance of motivation in promoting phonological skills. The data indicate that the pupils' encountered the greatest difficulty in rhyme production where the gap between high to low motivation pupils was preserved.

In conclusion, our results point to a great progress in phonological awareness The gap between the subgroups by motivation was not salient (the average of high motivation pupils is 79 out of 100 and the average of low motivation pupils is 75 out of 100 ).

In the first two measurements, a gap in phonological skills performance was noted between the high motivation pupils and the low motivation pupils that decreased in the third measurement. It can be assumed that participating in the intervention program benefited both low and highly motivated. It can be assumed that interactive nature of the program affected also the pupils' motivation level, making learning more enjoyable and interesting. The study findings are compatible with other phonological awareness training studies (Macaruso, Hook \& McCabe, 2006; Jiménez et al., 2007; van Daal \& Reitsma, 2000; Wise, Ring, \& Olson, 1999), which emphasize that phonological skills can be enhanced by explicit instruction. This instruction can be held prior to commencing reading acquisition or in parallel, as was the case in the current study. Following Hiebert (1996) studies, Tayler (1996) indicated that it is the teachers' role to help pupils develop the ability to recognize the phonemic structure of the words and to understand the correspondence between the graphemes and phonemes.

\subsection{Summery}

The current study shows on two important conclusions: first, At-Linguistic-Risk children necessitate an ade- 
quate multi-componential instructional environment in order to bridge literacy gaps their initial gaps. Second, Motivation facilitates and accelerates learning processes.

It is recommended to expand the sample of the study in order to calculate statistical significance. In addition, the motivation level of the pupils was determined before the program activation, but it could be change as a function of many factors (the tutor's motivation to teach and the pupil's achievement throughout the activation). Therefore, it could be interesting to examine the changes in motivation throughout the activation.

The improvement of the phonological component of the children who participated in this study was important in itself, but there is still a question that has to be answered: Has this improvement brought also to continuous progress in the field of reading comprehension skill? The study described here did not deal with this aspect, but the researcher, who is a native Arabic speaker, interviewed teachers of Second and Third Grades who taught the pupils who participated in the intervention and the Control Group. The teachers described constant progress among the pupils who participated in the study, and when they reached Third Grade, their abilities and grades in "reading comprehension" were similar to their classmates and they were not identified as "pupils at high linguistic risk" anymore. However, the pupils who were in the control group are still at high linguistic risk and find difficulty in reading acquisition. There is no doubt that it is worthwhile conducting longitudinal study to examine the development of reading, but there is no doubt also that this study raises a positive approach for the treatment of the great difficulty that the Arabic speaking pupils who are at high linguistic risk face when they start learning at first grade!

This study has an important implementation to the educational field: At-linguistic-Risk children reach first grade with a low phonological awareness, for that reason this should be treated in order to provide remedial teaching in time. In addition, those children should be treated in a different way and should have materials, which could help bridging these gaps, in order to develop like the other children.

Reading is the key for learning and acquiring new information. We should consider it as a key for our children's future, so we should treat any difficulties in an early age in order to open for them the horizons.

\section{References}

Abdelhadi, S., Ibrahim, R., \& Eviatar, Z. (2011). Perceptual Load in the Reading of Arabic: Effects of Orthographic Visual Complexity on Detection. Writing Systems Research, 3, 117-127. http://dx.doi.org/10.1093/wsr/wsr014

Abu-Rabia, S. (1999). The Effect of Vowels on the Reading Comprehension of Second- and Sixth-Grade Native Arab Children. Journal of Psycholinguistic Research, 28, 93-101. http://dx.doi.org/10.1023/A:1023291620997

Abu-Rabia, S. (2000a). Dyslexia. Israel: Faculty of Education, University of Haifa.

Abu-Rabia, S. (2000b). Effects of Exposure to Literary Arabic on Reading Comprehension in a Diglossic Situation. Reading and Writing, 13, 147-157.

Abu-Rabia, S. (2002). Reading in a Root-Based-Morphology Language: The Case of Arabic. Journal of Research in Reading, 25, 299-309. http://dx.doi.org/10.1111/1467-9817.00177

Abu-Rabia, S. (2003). The Influence of Working Memory on Reading and Creative Writing Processes in a Second Language. Educational Psychology, 23, 209-219. http://dx.doi.org/10.1080/01443410303227

Adams, M. J. (1991). Beginning to Read: Thinking and Learning about Print. Cambridge, MA: MIT Press.

Aikens, N. L., \& Barbarin, O. (2008). Socioeconomic Differences in Reading Trajectories: The Contribution of Family, Neighborhood, and School Contexts. Journal of Education Psychology, 100, 235-251.

Aram, D., \& Levin, I. (2001). Mother-Child Joint Writing in Low SES: Sociocultural Factors, Maternal Mediation, and Emergent Literacy. Cognitive Development, 16, 831-852. http://dx.doi.org/10.1016/S0885-2014(01)00067-3

Assink, E. M. H. (1994). Literacy Acquisition and Social Context. New York: Harvester Wheat Sheaf.

Ayari, S. (1996). Diglossia and Illiteracy in the Arab World. Language, Culture and Curriculum, 9, 243-253. http://dx.doi.org/10.1080/07908319609525233

Bentin, Sh. (1997). On the Connection between Phonology, Phonemic Awareness and Reading Processes. In Y. Shimron (Ed.), Studies in Language Psychology in Israel (pp. 184-202). Jerusalem: Magnes. (In Hebrew)

Blachman, B. A., Ball, E. W., Black, R., \& Tangel, D. M. (2000). Road to the Code: A Phonological Awareness Program for Young Children. Baltimore, MD: Paul H. Brookes Publishing Co.

Blachman, B.A. (2000). Phonological Awareness. In M. L. Kamil, P. B. Mosenthal, P. D. Pearson, \& R. Barr (Eds.), Handbook of Reading Research. New York: Longman.

Bowman, J. (1998). Technology, Tutoring and Improved Reading. English Update Newsletter Archives. 
Bryant, P. E., \& Bradley, L. L. (1983). Categorizing Sounds and Learning to Read: A Causal Connection. Nature, 301, 419421. http://dx.doi.org/10.1038/301419a0

Caravolas, M., Hulme, C., \& Snowling, M. J. (2001). The Foundations of Spelling Ability: Evidence from a 3-Year Longitudinal Study. Journal of memory and language, 45, 751-774. http://dx.doi.org/10.1006/jmla.2000.2785

Chang, C. Y. (2002). Does Computer-Assisted Instruction + Problem Solving = Improved Science Outcomes? A Pioneer Study. Journal of Education Research, 95, 143-151. http://dx.doi.org/10.1080/00220670209596584

Cobb, J. B. (2001). The Effects of Early Intervention Program with Pre-Service Teacher as Tutors on the Reading Achievement of Primary Grade at Risk Children. Reading Horizon, 41, 73-155.

Cole, J. M., \& Hilliard, V. R. (2006). The Effects of Web-Based Reading Curriculum on Children's Reading Performance and Motivation. Journal of Educational Computing Research, 34, 353-380. http://dx.doi.org/10.2190/H43W-1N3U-027J-07V5

Cotton, K. (2001). Computer-Assisted Instruction. School Improvement Research Series, Northwest Regional Educational Library, 10.

Ehri, L. C., Wunes, S. R., Willows, D. M., Schuster, B. V., Zadeh, Z. Y., \& Shanahan, T. (2001). Phonemic Awareness Instruction Helps Children Learn to Read: Evidence from the National Reading Panel's Meta-Analysis. Reading Research Quarterly, 36, 250-287. http://dx.doi.org/10.1598/RRQ.36.3.2

Elbaum, B., \& Vaughn, S. (2000) How Effective Are One-to-One Tutoring Programs in Reading for Elementary Students at Risk for Reading Failure? A Meta-Analysis of the Intervention Research. Journal of Educational Psychology, 92, 605619.

Garcia, M. R., \& Arias, F. V. (2000). A Comparative Study in Motivation and Learning through Print-Oriented and ComputerOriented Tests. Computer Assisted Language Learning, 13, 457-465. http://dx.doi.org/10.1076/0958-8221(200012)13:4-5;1-E;FT457

Hiebert, E. H. (1996). Creating and Sustaining a Love of Literature... and the Ability to Read It. In M. Graves, B. Taylor, \& P. van den Broek (Eds.), The First R (pp. 15-36). New York: Teachers College Press.

Hulme, C., Hatcher, P. J., Nation, K., Brown, A., Adams, J., \& Stuart, G. (2002). Phoneme Awareness Is a Better Predictor of Early Reading Skill than Onset-Rime Awareness. Journal of Experimental Child Psychology, 82, 2-28. http://dx.doi.org/10.1006/jecp.2002.2670

Hurford, D. P., Johnston, M., Nepote, P., Hampton, S., Moore, S., Neal, J., Mueller, A., McGeorge, K., Huff, L., Awad, A., Trato, C., Juliano, C., \& Huffman, D. (1994). Early Identification and Remediation of Phonological-Processing Deficits in First-Grade Children at Risk for Reading Disabilities. Journal of Learning Disabilities, 27, 647-659. http://dx.doi.org/10.1177/002221949402701005

Ibrahim, R. (2009). The Cognitive Basis of Diglossia in Arabic: Evidence from a Repetition Priming Study within and between Languages. Psychology Research and Behavior Management, 12, 95-105. http://dx.doi.org/10.2147/PRBM.S5138

Ibrahim, R., \& Aharon-Peretz, J. (2005). Is Literary Arabic a Second Language for Native Arab Speakers?: Evidence from a Semantic Priming Study. The Journal of Psycholinguistic Research, 34, 51-70.

http://dx.doi.org/10.1007/s10936-005-3631-8

Inbar, A., \& Ravid, Sh. (1995). Teaching Reading Skills at First Grade-A Teacher's Guide. Jerusalem: Tav-Lamed, and The Department of Teaching Programs.

Jiménez, J. E., Hernández-Valle, I., Ramírez, G., Ortiz Mdel, R., Rodrigo, M., Estévez, A., O’Shanahan, I., García, E., \& Trabaue Mde, L. (2007). Computer Speech-Based Remediation for Reading Disabilities: The Size of Spelling-to-Sound Unit in a Transparent Orthography. Spanish Journal of Psychology, 10, 52-67. http://dx.doi.org/10.1017/S1138741600006314

Khamis-Dakwar, R., \& Froud, K. (2007) Lexical Processing in Two Language Varieties: An Event-Related Brain Potential Study of Arabic Native Speakers. In M. Mughazy (Ed.), Perspectives on Arabic Linguistics XX (pp. 153-168). Amsterdam \& Philadelphia: John Benjamins. http://dx.doi.org/10.1075/cilt.290.13kha

Korat, A., \& Becher, A. (1997). Buds of Teaching Reading Skills. University of Tel Aviv, Mofet Institute, Ministry of Education, Culture and Sport. (In Hebrew)

Korat, A. (1998). Mother-Son Reciprocal Relations: Mother's Beliefs and the Development of Writing Texts for Children-A Comparison between Groups of Metsav. Ph.D. Thesis, Tel Aviv: Tel Aviv University. (In Hebrew)

Kozmenski, A., \& Kozmenski, L. (1999). Phonological Awareness and Success in Reading Acquisition. Milolit, Jerusalem: Beit Berl College.

Lapidot, M., Wohl, A., \& Tobol, L. (1996). A Phonological Awareness Test as a Tool for Reading Acquisition Predictor. Tel-Aviv: Tel-Aviv University. (In Hebrew) 
Liberman, I. Y., Shankweiler, O. Fisher, F. W., \& Carter. B. (1974). Explicit Syllable Explicit Syllable and Phoneme Segmentation in the Young Child. Experimental Child Psychology, 18, 201-212. http://dx.doi.org/10.1016/0022-0965(74)90101-5

Lombard, A. (1995). Parents and Family Are a Gate to Success: Past, Present and Future in the Itgar (Challenge) Program: Mother Training Program in Infancy Education. Jerusalem: The Hebrew University, Institute of Research in Education Development. (In Hebrew)

Maamouri, M. (1998). Language Education and Human Development. Arabic Diglossia and Its Impact on the Quality of Education in the Arab World. The Mediterranean Development Forum, Marrakesh: The World Bank.

Macaruso, P., Hook, P. E., \& McCabe, R. (2006). The Efficacy of Computer-Based Supplementary Phonics Programs for Advancing Reading Skills in At-Risk Elementary Students. Journal of Research in Reading, 29, 162-172. http://dx.doi.org/10.1111/j.1467-9817.2006.00282.x

Makhoul, B. (2006). Research in the Process of Acquisition of Reading Skills in Arabic in the Framework of a Guided Tutorship. Ph.D. Dissertation, The Hebrew University of Jerusalem. (In Hebrew)

Makhoul, B. (2012). Research in the Process of Acquisition of Reading and Writing in Arabic According to the Interactive Model in the First Grade. A Post-Doctoral Dissertation, University of Haifa and The Center for Educational Technology, CET. (In Hebrew)

Mayer, A., \& Rose, D. H. (1998). Learning to Read in the Computer Age. Cambridge, MA: Brookline Books.

McCormick, S. (1994). A Nonreader Becomes a Reader. A Case Study of Literacy Acquisition by a Severely Disabled Reader. Reading Research Quarterly, 31, 268-289. http://dx.doi.org/10.2307/747809

Ministry of Education (1991). A Teacher's Guide for Al-Raed for the First Grade. Haifa: The Department of Teaching Programs. (In Arabic)

Ministry of Education (1989). Program of Teaching Arabic Language and Literature for the Arab Elementary Schools, Grades 1-6. Jerusalem: The Department of Teaching Programs. (In Hebrew)

Olshtain, E., \& Makhoul, B. (2010). Phonological Awareness in a Computerized-Tutorship Environment among Arabic Speaking Children. In A. Kort, \& D. Aram (Eds.), Orientation and Language: Reciprocal Relations, Bilingualism and Difficulties (pp. 337-355). Jerusalem: Magnes Publishing. (In Hebrew)

Olshtain, E., \& Zuzuvski, R. (2003). The International Study for Reading Literacy: Executive Summary. The Ministry of Education, Chief Scientist Bureau. (In Hebrew)

Rosenhoiz, Y. (1998). Acquisition of Morphology and Syntax of Spoken Arabic as a Mother Tongue: Initial Results. In Hilkat Lashon, 27. Tel Aviv: Levinsky College for Education. (In Hebrew)

Roth, S. F., \& Beck, I. L. (1997). Theoretical and Instructional Implications of the Assessment of Two Microcomputer Word Recognition Programs. Reading Research Quarterly, 22, 197-218. http://dx.doi.org/10.2307/747665

Rush, K. L. (1999). Caregiver-Child Interactions and Early Literacy Development of Preschool Children from Low-Income Environments. Topics in Early Childhood Special Education, 19, 3-14. http://dx.doi.org/10.1177/027112149901900101

Saiegh-Haddad, E. (2003) Linguistic Distance and Initial Reading Acquisition: The Case of Arabic Diglossia. Applied Psycholinguistics, 24, 431-451. http://dx.doi.org/10.1017/S0142716403000225

Saiegh-Haddad, E. (2004). The Impact of Phonemic and Lexical Distance on the Phonological Analysis of Word and Pseudo Words in a Diglossic Context. Applied Psycholinguistics, 25, 495-512. http://dx.doi.org/10.1017/S0142716404001249

Saiegh-Haddad, E. (2005). Correlates of Reading Fluency in Arabic Diglossic and Orthographic Factors. Reading and Writing, 18, 559-582. http://dx.doi.org/10.1007/s11145-005-3180-4

Schneider, W., Roth, E., \& Ennemoser, M. (2000). Training Phonological Skills and Letter Knowledge in Children at Risk for Dyslexia: A Comparison of Three Kindergarten Intervention Programs. Journal of Educational Psychology, 92, 284295. http://dx.doi.org/10.1037/0022-0663.92.2.284

Smith, S. B., Simmons, D. C., \& Kameenui, E. J. (2000). Synthesis of Research on Phonological Awareness: Principles and Implications for Reading Acquisition. US Office of Special Education Programs, National Center to Improve the Tools of Education.

Snow, C. E., Burns, S. M., \& Griffin, P. (Eds.) (1998). Preventing Reading Difficulties in Young Children. National Research Council, National Academy Press.

Stanovich, K. E., Cunningham, A. E., \& Cramer, B. R. (1984). Assessing Phonological Awareness in Kindergarten Children: Issues of Task Comparability. Journal of Experimental Child Psychology, 38, 175-190.

http://dx.doi.org/10.1016/0022-0965(84)90120-6

Taylor, B. M. (1996). Looking beyond Ourselves to Help All Children Learn to Read. In M. F. Graves, P. van den Broek, \& B. M. Taylor (Eds.), The First R: Every Child's Right to Read (pp. 62-69). New York and Newark: Teachers College Press and International Reading Association. 
van Daal, V., \& Reitsma, P. (2000). Computer-Assisted Learning to Read and Spell: Result from Two Pilot Studies. Journal of Research in Reading, 23, 181-193. http://dx.doi.org/10.1111/1467-9817.00113

Weismer, S. E. (1990). Aspects of Meta-Linguistic Abilities in Specific Language Impairment (Developmental Aphasia) \& Dyslexia. In H. Grimm (Eds.), Linguistic Disorders and Pathologies, an International Handbook (pp. 773-787). Berlin: Walter de Gruyter and Co.

Wright, D. J. (1998). Choosing to Read, Overcoming Reading Apathy. Teaching and Change, 5, 225-231.

Yopp, H. K (1992). Developing Phonemic Awareness in Young Children. The Reading Teacher, 45, 696-703.

Yopp, H. K. (1988). The Validity and Reliability of Phonemic Awareness Tests. Reading Research Quarterly, 23, $159-177$. http://dx.doi.org/10.2307/747800

Yopp, H. K. (1995). A Test for Assessing Phonemic Awareness in Young Children. The Reading Teacher, 29, $20-29$. http://dx.doi.org/10.1598/RT.49.1.3 